\title{
Assessment of Condition Monitoring Techniques for Offshore Wind Farms
}

\author{
Edwin Wiggelinkhuizen \\ Theo Verbruggen \\ Henk Braam \\ Luc Rademakers \\ Jianping Xiang* \\ Simon Watson* \\ * Loughborough University (CRES), UK
}

ECN-W--08-034

This article has been published online 24 June 2008, in Journal of Solar Energy Engineering (Vol.130, Iss.3). 





\section{Edwin Wiggelinkhuizen Theo Verbruggen Offshore Wind Farms}

Henk Braam Luc Rademakers

Energy Research Centre of the Netherlands (ECN) (NL) Petten NL-175526, Netherlands

\section{Jianping Xiang Simon Watson}

\section{Assessment of Condition Monitoring Techniques for}

This paper discusses the results of an extensive investigation to assess the added value of various techniques of health monitoring to optimize the maintenance procedures of offshore wind farms. This investigation was done within the framework of the EU funded Condition Monitoring for Offshore Wind Farms (CONMOW) project, which was carried out from 2002 to 2007. A small wind farm of five turbines has been instrumented with several condition monitoring systems and also with the "traditional" measurement systems for measuring mechanical loads and power performance. Data from vibration and traditional measurements, together with data collected by the turbine's system control and data acquisition (SCADA) systems, have been analyzed to assess (1) if failures can be determined from the different data sets; (2) if so, if they can be detected at an early stage and if their progress over time can be monitored; and (3) if criteria are available to assess the component's health. Several data analysis methods and measurement configurations have been developed, applied, and tested. This paper first describes the use of condition monitoring if condition based maintenance is going to be applied instead of only scheduled and corrective maintenance. Second, the paper describes the CONMOW project and its major results, viz., the assessment of the usefulness and capabilities of condition monitoring systems, including algorithms for identifying early failures. Finally, the economic consequences of applying condition monitoring systems have been quantified and assessed.

[DOI: $10.1115 / 1.2931512]$

Keywords: condition monitoring, operation and maintenance, wind energy

\section{Introduction}

As offshore wind turbines are located at remote sites under harsh conditions, the demand for high reliability and low operational costs becomes higher than for onshore turbines. Studies carried out at the end of the 1990s and also more recent studies, e.g., Ref. [1], showed that the costs for the operation and maintenance $(\mathrm{O} \& \mathrm{M})$ of offshore wind farms are substantially higher than for onshore wind turbines. O\&M costs contribute about 25-30\% to the energy generation costs, and a considerable percentage is caused by unexpected failures leading to corrective maintenance. These figures emphasized the need for optimizing the O\&M program for offshore wind farms. Possibly, the use of adequate diagnostics based on condition monitoring techniques could contribute to such an optimization. By doing so, the number of inspection visits and corrective maintenance actions can possibly be lowered, including the related costs and downtime.

Condition monitoring techniques have been used successfully for a long time in many branches of industry. Recently, several different systems became commercially available for application to wind turbines, such as vibration monitoring systems for bearings and gear boxes and online oil monitoring systems. Next to the information provided by vibration monitoring systems, wind farm operators also receive information about the turbine's health from system control and data acquisition (SCADA) systems and from inspection and maintenance reports. In 2001, only little experience was (publicly) available about the added value of the condition monitoring techniques and methods for signal analyses.

Contributed by the Solar Energy Engineering Division of ASME for publication in the Journal of Solar Energy Engineering. Manuscript received May 25, 2007; final manuscript received March 7, 2008; published online June 24, 2008. Review conducted by Spyros Voutsinas. Paper presented at the European Wind Energy Conference, 2007
To investigate whether cost effective condition monitoring techniques can be applied on a large scale for offshore wind energy applications, the European project Condition Monitoring for Offshore Wind Farms (CONMOW) [2] was executed from November 2002 to July 2007.

Section 2 of this paper provides a general introduction into maintenance concepts and the role of condition based maintenance. It explains the use of online and offline condition monitoring when applying condition based maintenance. The CONMOW project approach is described in Sec. 3. Project results are given in Secs. 4-6. Special attention is given to processing of time series, SCADA data, and data from vibration monitoring systems. In Sec. 7 , an economic assessment is made of the added value for offshore wind energy.

\section{Condition Based Maintenance}

2.1 Maintenance Types. At a general level, maintenance can be subdivided into preventive and corrective maintenance. Corrective maintenance is performed after a breakdown or if an obvious fault has occurred. Preventive maintenance is intended to prevent equipment breakdown and consists of repair, service, or component exchange. Preventive and corrective maintenance can be split up further. For wind turbine technology, the following subcategories seem to be appropriate (see Fig. 1).

- Preventive maintenance:

- Calendar based maintenance, based on fixed time intervals or on fixed numbers of operating hours

- Condition based maintenance, based on the actual health of the system

- Corrective maintenance:

- Planned maintenance, based on the observed degradation 



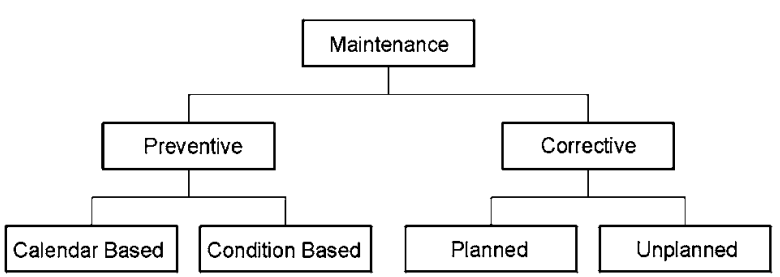

Fig. 1 Schematic overview of different maintenance types

of a system or component (a component failure is expected in due time and should be maintained before it occurs)

- Unplanned maintenance, necessary after an unexpected failure of a system or component

Both condition based preventive maintenance and planned corrective maintenance are initiated based on the observed status or degradation of a system. The main difference between these two categories is that condition based preventive maintenance is foreseen in the design, but it is not known in advance when the maintenance has to be carried out, while the occurrence of planned corrective maintenance is not foreseen at all.

2.2 Condition Monitoring Application. Condition based maintenance requires a proper determination and prognosis of the health of the system, so-called condition monitoring. Depending on the type of system and component, a wide variety of condition monitoring methods and techniques is available. For instance, offline, one can perform periodic visual inspections, analyze oil samples, or vibration measurements. Another option is to permanently install systems that are dedicated to perform certain measurement and analysis tasks and that automatically report analysis results and events (alarms and warnings) to operators. Such systems are referred to as online condition monitoring systems. Another source of information for health determination is operational data from SCADA systems, e.g., the number of starts and stops, development of temperatures over time, or occurrence of alarms.

When implementing a condition based maintenance strategy, one can use all different sources of information to determine the turbine's "health" and is not limited to using online condition monitoring systems only. In practice, often, a combination of different monitoring methods is applied for condition based maintenance, depending on specific technical, logistic, or regulatory aspects. Still, too often, online condition monitoring is assumed to be a synonym for condition based maintenance.

Furthermore, it should be noted that condition based maintenance mainly makes sense if

(1) the design life of the component is shorter than that of the entire turbine, meaning that repair or replacement of the component is foreseen, but it is not clear when;

(2) cost savings are expected compared to scheduled and corrective maintenance only; and

(3) it is clear that the dominant cause of failure is indeed wear, meaning gradual degradation in time toward the end of the design lifetime; this is contrary to abrupt damage due to extreme events, design, or manufacturing errors and the like.

Gearbox oil, as an example of (1), will be replaced several times during the turbine lifetime. Condition based maintenance can be applied to determine if the oil needs to be changed after four years (calendar based) or maybe after seven years (condition based). This could save one oil change within the turbine lifetime.

So-called "safe life components," such as rotor blades, main bearing, or gearbox, usually have a design lifetime that is at least the same as that for the turbine, which is typically $20-25$ years. If such components fail during the lifetime of the turbine, the failure

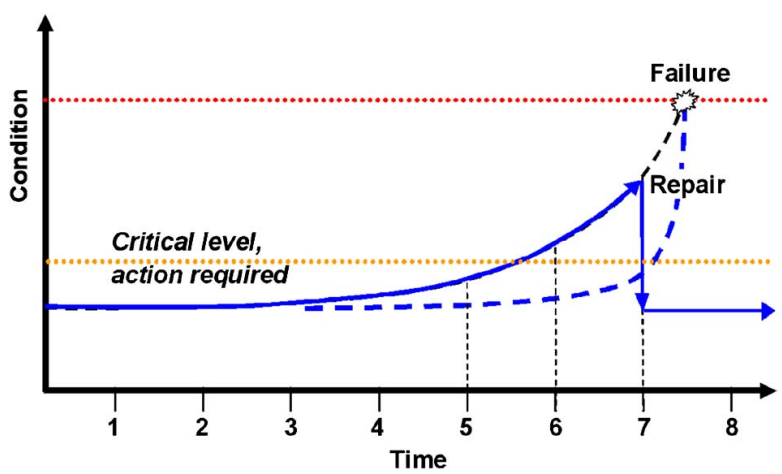

Fig. 2 Condition based maintenance based on inspections at regular inspection intervals (solid line) or on online monitoring (dashed line)

cause is usually extreme loading, poor installation, or manufacturing, or other unforeseen conditions, such as lightning or accidents. Large repairs or replacements of safe life components are not foreseen within the turbine lifetime; therefore, monitoring the health and degradation is difficult to justify. One reason, however, for using condition monitoring systems in the case of safe life components is minimizing the consequence damage. In case unexpected failures show up, they can be detected at an early stage, and catastrophic failures can be avoided.

An example of a successful application of offline condition based maintenance is schematized in Fig. 2 with the blue curve: At $t=5$, a significant change in the condition (solid blue line) is observed. At the next inspection, at $t=6$, a critical level ("yellow light") is exceeded and action should be taken. Repair is carried out during the next preventive maintenance at $t=7$. Offline inspection is sufficient since (a) the failure progresses slowly and (b) the speed of progress is known from early experiences.

Online condition monitoring makes sense if the fault would progress faster than the time between two inspections, as illustrated by the dashed blue line. In this case, it is possible to prevent component failure and possible consequence damage, e.g., by shutting down the system. Since the fault progresses so fast, there is no opportunity to better plan the preventive maintenance actions. Online monitoring becomes more and more important if inspection intervals become larger, as is the case for offshore wind farms. The inspection intervals for offshore wind farms are larger than those for onshore turbines, typically once per year instead of twice a year. So-called "sudden failures" are difficult to detect at an early stage at all with condition monitoring, both online and offline. Therefore, condition based maintenance should not be applied for sudden failures.

2.3 Condition Monitoring Requirements. A general definition of condition monitoring is the process of monitoring a parameter of condition in machinery, such that a significant change is indicative of a developing failure. From this definition, three requirements have been derived, which condition monitoring systems should meet for a successful application in condition based maintenance.

1. Detection of failure mechanism. It has to be clear what the failure mechanism is and which diagnostic means should be available to detect the failure mechanism and its development. Components can fail in different ways and a failure mode, effect, and criticality analysis (FMECA) (see also Sec. 5.1) can be performed to determine all possible failure modes, conceive mitigating measures, and, if possible, determine "early indicators" that represent the development of the failure and the system condition.

2. Detection on time. The use of condition monitoring allows maintenance to be scheduled or other actions to be taken to 

minimize the consequences of failure before the failure occurs. This means that changes in the machinery condition need to be detected on time and prognoses need to be made about future developments in order to take mitigating measures. On time in this respect means detection at an early stage of the failure development when no severe damage has occurred yet but immediate repair is needed.

3. Measurable criteria. In fact, just measuring the failure and its development is not enough; clear and measurable criteria should be defined before it can be decided that actions should be taken. Simply said, green, yellow, and red light should be available to assess the condition monitoring results. Assuming an indicator that increases with a declining machinery condition, it should be clear what the maximum acceptable level for the system is said to be healthy (green light) and what level should be exceeded before the monitoring system indicates that a failure is developing (red light). To determine such criteria, long-term experiences, including measurements during situations of failures, need to be available. The situation becomes even more complex if (like in wind energy) the failure development is caused by stochastic loading.

\section{CONMOW Project}

3.1 Objectives. The CONMOW project has been defined to investigate whether online condition monitoring techniques and already available data, such as SCADA data, PLC measurements, and inspection reports, provide sufficient information to change partly from corrective and scheduled maintenance to condition based maintenance for large offshore wind farms. In fact, during the execution of the project, it was assessed to what extent the various condition monitoring techniques available for wind turbines meet the three requirements given in Sec. 2.3. Secondly, the CONMOW project had the ambition to implement the lessons learned into a wind farm SCADA system and to test it over a longer period. Finally, the project results had to be submitted to standardization committees, e.g., the work group working on the wind turbine communication standard: IEC61400-25.4 [3].

3.2 Consortium and Structure. A project team has been established, representing the following:

- suppliers of vibration monitoring systems: Gram \& Juhl A/S, DK and Prüftechnik CM GmbH, D

- suppliers of online oil monitoring systems: Pall Europe Ltd., E

- wind turbine manufacturers: Nordex Energy GmbH, D

- suppliers of SCADA systems: DTU-Risø National Laboratory, DK and Garrad Hassan and Partners Ltd., UK

- R\&D institutes: Energy Research Centre of the Netherlands (ECN), NL and Loughborough University, CREST, UK.

The project was separated into two main phases. The first phase comprised the extensive instrumentation of a single turbine, not only with online condition monitoring techniques but also with the "traditional" measurement systems like load measurements. The objective of this phase was to carry out an extensive measurement campaign on a pitch controlled turbine with variable speed under normal operating conditions. Based on these data, interrelationships were determined between turbine parameters and condition monitoring results. This showed whether these parameters could also provide information on the machine condition that is comparable or complementary to condition monitoring systems.

In the second phase, the methods had to be applied on a larger scale in a wind farm. The systems had to be tested over a longer period of time and continuously improved. Also, a sensitivity study had to be performed to assess the potential cost benefits of applying condition monitoring in a typical offshore wind farm at the North Sea.
3.3 Execution and Bottlenecks. The execution of the CONMOW project was hampered mainly by nontechnical issues. The most important ones were the following.

- An ongoing measurement campaign in phase 1 on a GE1.5S turbine in Zoetermeer had to be terminated after one year. A measurement campaign in phase 2, also foreseen on GE $1.5 \mathrm{~S}$ wind turbines, was finally substituted by a new campaign on five Nordex N80/2.5MW turbines at ECN wind turbine test site Wieringermeer (EWTW) in the Netherlands. The campaigns of phases 1 and 2 were combined for reasons of time.

- In order to configure the vibration monitoring systems, the kinematical data of the gearbox and bearings were necessary as input. Obtaining these data took much longer than expected, and insufficient time was left for evaluation. As a result, the configured systems could not be fully tested and no improvements could be proposed.

- The oil monitoring system was not implemented because for this project no permission was granted for the installation of the hardware.

- It was foreseen that several fault situations could be introduced during the measurement campaign. However, due to contractual matters, this was not possible. Only two relevant random failures were observed in this project during the measurements at the GE1.5S turbine and one off-design condition at a N80 turbine at the EWTW.

- For the reasons mentioned above, the knowledge gained during phase 1 was insufficient for implementing new algorithms in a wind farm SCADA system.

The project team learned that research projects on condition monitoring can only be done if all parties (turbine owner, turbine manufacturer, component supplier, and research parties) collaborate from the beginning on and are willing to share relevant information. The project team also learned that even if instrumentation is installed successfully in the turbines, not all experiments can be carried out. There is no guarantee that degradation or failures show up within the duration of the project and imposing fault situations was not allowed, as this could damage the turbines. Consequently, within the CONMOW project, not all data needed for developing new algorithms were acquired.

3.4 Project Results. The following results have been achieved in the CONMOW project (Ref. [5]), which are discussed in more detail in the following sections.

1. First, an inventory was made of the state-of-the-art condition monitoring techniques that are presently available and could be applicable for wind turbines [4]

2. Prior to the measurement campaign, a measurement plan was written in order to agree with all participants on, among others, the approach, list of signals, instrumentation, reporting of data, progress and results, dissemination of data, and health, safety, and environment (HSE) aspects. A relevant part of the instrumentation plan was the FMECA. This FMECA was performed to identify vulnerable systems and to assess if meaningful condition monitoring systems could be applied to reduce failure frequencies and/or limit the consequences of failure (and thus the criticality).

3. An extensive measurement campaign was carried out at the N80 turbines at the EWTW test site of ECN. The measured data (SCADA data, data from load measurements, and highfrequency data from online condition monitoring systems) were analyzed in various ways to detect degradation of components, to assess the usefulness of the systems, and to develop new algorithms.

4. Since it was not allowed to introduce fault situations in the turbines, such as pitch errors, yaw misalignment, or rotor imbalance, several simulations were made to investigate possible relationships between the failed situation (e.g., rotor 

mass imbalance) and several "measurable parameters" (e.g., nacelle vibrations).

5. Finally, an economic assessment was made of the added value of condition monitoring techniques for wind turbines. It was assumed that condition monitoring systems are able to limit the criticality of failures and the impact on O\&M costs, and availability was quantified.

\section{State-of-the-Art CM Techniques}

There is a wide number of condition monitoring techniques used throughout the industry $[4,5]$. To date, techniques such as vibration and process parameter analysis have been applied to wind turbines. From the research to date, the most promising areas for the application of condition monitoring of wind turbines, particularly moving offshore, seem to be

- vibration, acoustic, and fiber optic strain analysis of the blades

- acoustic and vibration analysis of selected drive-train components

- thermographic analysis of electrical components

- analysis of oil quality (both online and/or via regularly scheduled laboratory analysis)

- time and frequency domain analysis of the electrical power

- trending of key component response functions

- inclusion of visual/aural examination to enhance maintenance planning

\section{Measurement Setup}

5.1 Instrumentation Plan and FMECA. Prior to the actual instrumentation, a so-called instrumentation plan has been made. The actual instrumentation has been based largely on the results of a FMECA. A FMECA is generally intended as a structured approach to identify all possible failure modes of a system, their failure rate, and their severity in terms of costs, downtime, safety, etc. (see also Ref. [6]). In general, the criticality is expressed as the product of failure rate and severity. The FMECA results in a list of components, subsystems, and failure modes that contribute most to maintenance costs. Measures can be conceived to reduce failure rates and/or severity of the most critical failure modes.

The first step in a FMECA is to make a structural breakdown of the entire turbine and to conceive all possible failure modes for each component; for example,

\section{Wind farm}

\section{$\rightarrow$ Wind turbine}

\section{$\rightarrow$ Main systems}

\section{$\leftrightarrow$ Components}

\section{$\leftrightarrow$ Failure modes}

Next, for each failure mode, the failure rate should be determined, either as absolute values (e.g., annual average failure frequency) or in a more qualitative way, e.g., from "high" (expected to occur more than once in a year) to (low) (not expected to occur during the turbine lifetime).

Within the CONMOW project, the severity was expressed in terms of seven different Failure Repair Classes (F-1-F-7). Each repair class determines among others the labor costs, costs for spare parts, costs of equipment, and revenue losses (see Table 1). Special attention was paid to the application of condition monitoring as a means to reduce the severity of failure modes. It was analyzed for the different failure modes if condition monitoring systems (in theory) are able to assign a lower failure repair class
Table 1 Classification of failure repair classes

\section{Failure repair class}

F-1: Alarm with remote rese

F-2: Alarm with repair

F-3: Alarm with replacement

F-4: Service with repair

F-5: Service with replacements

F-6: Failure of large components

F-7: Lightning strike

to them. A generator bearing failure, for instance, can cause consequence damage when it is not detected in an early stage. This might result in a replacement of the generator, which is classified as failure repair class F-6. This implies high repair costs and production loss. Application of a condition monitoring system could reduce the failure class from F-6 to F-5, which means that the repair itself can be done on site by the replacement of the bearing as planned maintenance, which reduces production loss.

When carrying out the FMECA, the project team recognized that in some situations, application of condition monitoring systems, indeed, has the potential to reduce the failure repair classes of different failure modes, but no suitable condition monitoring systems were found in Ref. [4] that were proven in practice. Therefore, the project team also classified the capabilities of condition monitoring systems, as given in Table 2, where five categories of $\mathrm{CM}$ systems have been assigned, each with a different potential on a combination of three aspects.

If we assume the generator bearing again, for fast running bearings, condition monitoring techniques are available from the market and the potential for cost reduction is considered high, as shown in Tables 2 and 3. For slow running pitch bearings, however, a condition monitoring system is presently not available.

Examples of failure modes moving to lower failure repair classes and the potential of condition monitoring systems are given in Table 3. Reduction of the failure repair class holds for the oil system concerning failure mode "insufficient lubrication." However, for two other failure modes mentioned for the oil system, no potential reduction is seen. For the electrical pitch system, some failures can be made less severe and some potential for cost reduction exists. However, condition monitoring techniques are not available yet (CM-4). In total, 56 possible failure modes have been listed, divided over 27 components. These results are reported in more detail in Ref. [2].

5.2 Overall Measurement Setup. Five N80 turbines at the ECN test site EWTW were instrumented for the CONMOW project. The following measurement systems are operational (see Fig. 3):

- five different drive-train vibration monitoring systems (three Prüftechnik and two Gram \& Juhl), producing time series and spectra of bearings and gearboxes

Table 2 Classification of CM potential

\begin{tabular}{lccc}
\hline \hline & \multicolumn{3}{c}{ Aspects } \\
\cline { 2 - 4 } Categories & $\begin{array}{c}\text { Early fault } \\
\text { detection } \\
\text { possible }\end{array}$ & $\begin{array}{c}\text { Detection } \\
\text { tools/instruments } \\
\text { available }\end{array}$ & $\begin{array}{c}\text { Potential } \\
\text { maintenance cost } \\
\text { reduction }\end{array}$ \\
\hline CM-1 $^{\text {a }}$ & + & + & ++ \\
CM-2 $^{\text {a }}$ & + & + & + \\
CM-3 $^{\text {b }}$ & + & - & ++ \\
CM-4 $^{\text {b }}$ & + & - & + \\
CM-5 & - & - & - \\
\hline \hline
\end{tabular}

${ }^{\mathrm{a}} \mathrm{CM}$ available on the market.

${ }^{\mathrm{b}} \mathrm{CM}$ techniques under development. 

Table 3 Examples of failure repair classes and $\mathrm{CM}$ potential for selected failure modes

\begin{tabular}{|c|c|c|}
\hline Failure mode & Failure class & Potential \\
\hline \multicolumn{3}{|l|}{ Generator bearing } \\
\hline Surface fatigue failure & $\mathrm{F}-6 \Rightarrow \mathrm{F}-5$ & CM-1 \\
\hline Fretting & $\mathrm{F}-6 \Rightarrow \mathrm{F}-5$ & CM-1 \\
\hline False brinelling & $\mathrm{F}-6 \Rightarrow \mathrm{F}-5$ & CM-1 \\
\hline Wear & $\mathrm{F}-6 \Rightarrow \mathrm{F}-5$ & CM-1 \\
\hline \multicolumn{3}{|l|}{ Oil circuit } \\
\hline Insufficient lubrication & $\mathrm{F}-6 \Rightarrow \mathrm{F}-5$ & CM-1 \\
\hline Insufficient cooling & $\mathrm{F} 2$ & N/A \\
\hline Filter blocked & F5 & N/A \\
\hline \multicolumn{3}{|l|}{ Electrical pitch system } \\
\hline $\begin{array}{l}\text { Failure of motor controller } \\
\text { or motor/reduction box }\end{array}$ & $\mathrm{F}-3 \Rightarrow \mathrm{F}-2$ & $\mathrm{CM}-4$ \\
\hline Failure of battery charger & F-3 & \\
\hline \multicolumn{3}{|l|}{ Insufficient battery capacity } \\
\hline Damage of bearing & F-6 & CM-5 \\
\hline
\end{tabular}

- load measurement systems for blades and towerfrom a single turbine $(\mathrm{ECN})$, producing time series at $32 \mathrm{~Hz}$

- system for measuring meteo data from a nearby meteo mast (ECN), at $4 \mathrm{~Hz}$

- measurement system to acquire operational data from all turbines (ECN, Nordex), at $25 \mathrm{~Hz}$

From other sources, the following data are available:

- operational statistics of all turbines (Nordex), $10 \mathrm{~min}$ statistics

- simulation data of fault conditions with GH BLADED.

High frequency measurement data and statistics from condition monitoring systems and from the traditional measurements have been collected since November 2005. The partners had online access to measurement data and analysis results. As already mentioned earlier, the oil monitoring system was not implemented because for this project no permission was granted for the installation of the hardware.

5.3 Drive-Train Vibration Monitoring. Prüftechnik Condition Monitoring $\mathrm{GmbH}$ has installed one VIBROWEB ${ }^{\circledR}$ XP certified $\mathrm{CM}$ system in one N80 turbine and two VIBNODE $^{\circledR}$ systems, newly developed for smaller wind turbines in two N80 turbines. The VIBNODE $^{\circledR} \mathrm{CM}$ system is cheaper and does not feature additional functions as rotational (re-)sampling and measuring in two operational states (according to GL regulations [7]). Instead, it continuously measures the vibration behavior and performs real-time diagnosis and preliminary evaluations over the whole operating range, thereby reducing the amount of data for a later offline analysis in the diagnostic center (see also Ref. [8]). The system has been shown to detect phenomena, e.g., high vibration levels, outside of the two operating states as applied in certified systems. Within the CONMOW project, the system has shown high vibration levels in one of the Nordex turbines. Inspections revealed that the cause was generator misalignment, and action was taken to realign the high-speed shaft.

Gram \& Juhl A/S has applied the turbine condition monitoring $\left(\mathrm{TCM}^{\circledR}\right)$ system on two Nordex turbines. Similar to the analysis of SCADA data, it is concluded that no failures occurred during the measurements that could be detected by the $\mathrm{TCM}^{\circledR}$ system. In this project, Gram \& Juhl also optimized their automatic fault frequency detection algorithms and measurement setup model, so that faults can be detected earlier.

Both the VIBNODE ${ }^{\circledR}$ systems and the Gram \& Juhl M system use displacement sensors at the low-speed section of the drive train, e.g., main bearing, which proved to be superior to vibration sensors because of the slow rotational speeds. With the Prüftechnik $\mathrm{CM}$ system, axial movements and vibrations of the planet carrier in the gear unit have been measured using displacement sensors.

During the 1.5 year monitoring period on the five Nordex turbines, only one failure occurred in the CM systems caused by a defective flash disk. Also, for the other measurement systems, only a single failure occurred caused by broken wiring of the blade load monitoring.

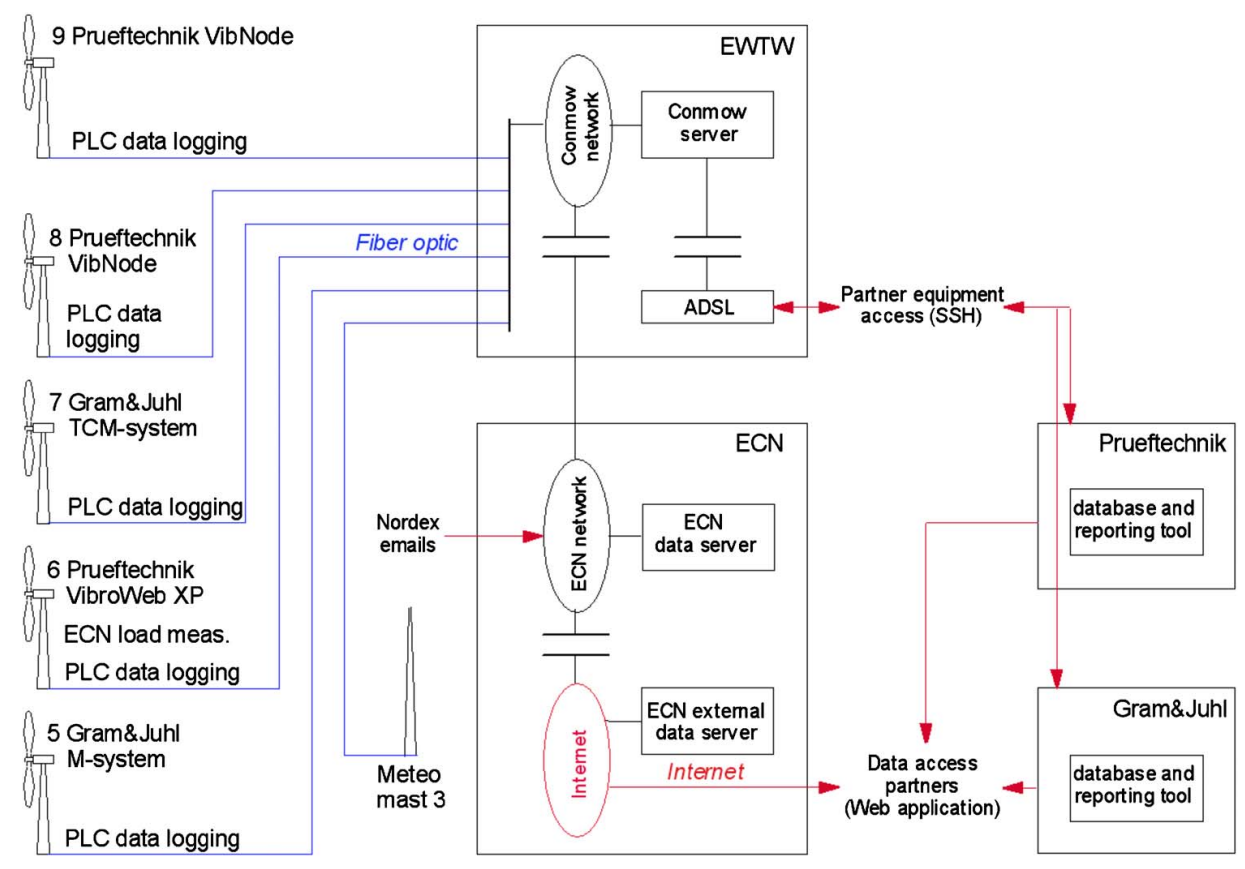

Fig. 3 Schematic overview of measurement and communication infrastructure 



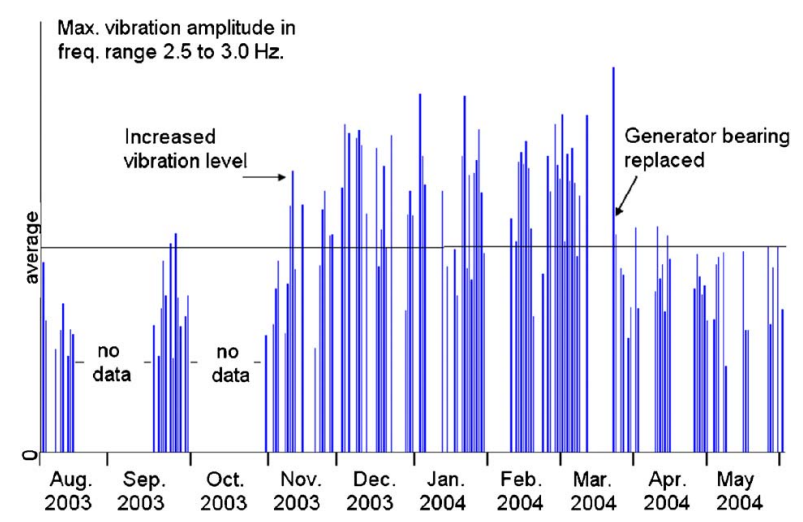

Fig. 4 Maximum daily amplitude of the wavelet fast Fourier transform (FFT) filtered GE $1.5 \mathrm{~S}$ wind turbine power output within the frequency range $2.5 \mathrm{~Hz}$ and $3.0 \mathrm{~Hz}$

\section{Analysis Results}

6.1 Time Series Processing Algorithms. The data analysis has focused on high-speed measurements of the electrical power output and of the pitching and yawing mechanism. Also a variety of signals from the SCADA system, both time series and statistics, have been analyzed.

Both theory $[9,10]$ and practice [11] suggest that asymmetries, unbalance, or faulty components can show up as specific frequencies in the electrical power output signal: (1) Dynamic eccentricity and dissymmetries of the rotor shape that influence the air-gap permeance cause the electrical power to vary with the rotor mechanical speed. (2) An asymmetrical rotor resulting in unbalanced rotor currents causes power variations with the slip frequency. (3) Rotor torque variations, for instance, due to rotor imbalance or abnormalities in the drive train, could be found in the power output during periods of almost constant rotor speed. As these power variations are irregular and nonstationary and the measurements cannot be easily controlled [12,13], CREST has developed a particular algorithm that employs both discrete and continuous wavelet transforms. A Morlet wavelet is used to extract a particular signature in the wind turbine power output sampled at $32 \mathrm{~Hz}$. To monitor the mechanical elements, it was decided to observe the trend in the rms values, as the maximum amplitudes of the wavelet coefficients showed a similar trend. Practical experience from a large population of turbines should provide sensible bounds for healthy operation and various stages of malfunctioning or damaged components.

Using the algorithms outlined above, it was possible to detect evidence of damage by an analysis of the wind turbine power signal. Examples are given in Figs. 4 and 5.

The amplitude of the Fourier transformed wavelet component in the frequency range of $2.5-3 \mathrm{~Hz}$ of the power output of the GE1.5S wind turbine in Fig. 3 shows an increase in November 2003. In January 2004, a generator misalignment was noted, and an attempt was made to correct this. This attempt was not successful, and in March 2004, the generator bearing failed. When the bearing was replaced in May 2004, the amplitude was reduced. It can be seen that this technique detected the misalignment at least three months before failure occurred.

Figure 5 indicates some evidence that high amplitudes of the Fourier transformed wavelet component in the frequency range $6.5-7.5 \mathrm{~Hz}$ of the power output of one of the Nordex N80 wind turbines existed from January to May 2006.

As Prüftechnik detected a mechanical vibration incitation associated with the generator bearing in December 2005, we believe it is possible that pulsating torque signals are produced due to the fluctuation in the permeance of the air gap. This may be caused by a shaft misalignment problem although this needs further investi-

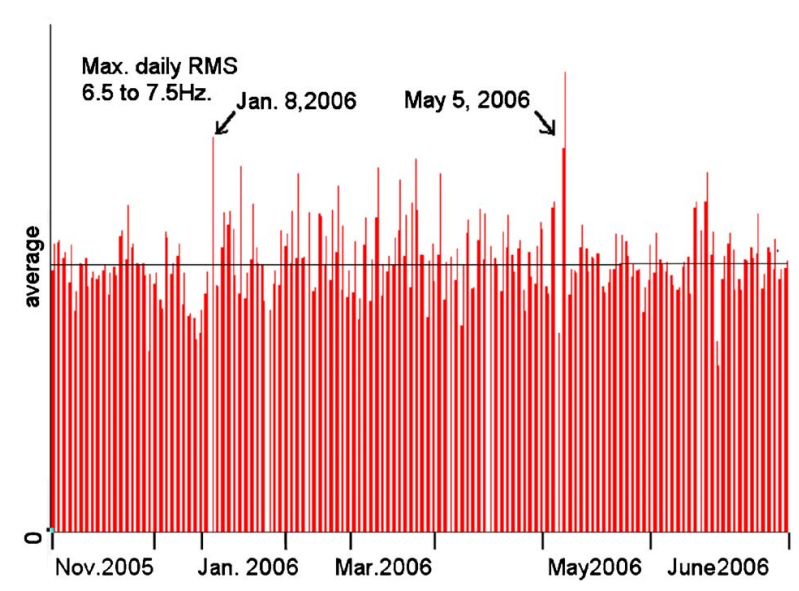

Fig. 5 Maximum daily rms of one of the wavelet filtered Nordex $\mathrm{N} 80$ wind turbine power outputs within the frequency range $6.5 \mathrm{~Hz}$ and $7.5 \mathrm{~Hz}$

gation, particularly with regard to information on corrective maintenance carried out in May 2006. It was concluded that processing the $32 \mathrm{~Hz}$ measurement data indeed revealed changes in vibration amplitudes and thus met requirement 1 in Sec. 2.3. However, due to the limited measurement time and due to the fact that no similar observations were available from other measurements, no criteria (requirement 3: green, yellow, and red light) could be applied when to carry out maintenance on time, and no prediction could be made how the degradation would develop over time (criterion 2).

6.2 SCADA Data Processing. Detrending of wind turbine SCADA data has been looked at as a way of picking out potential deviations from "normal" behavior. Figure 6 shows an example of 10 min averaged temperature measurements on a generator bearing of one of the Nordex N80 turbines as a function of power output, normalized at rated power.

To enhance the trend, the data have been linearly corrected for ambient temperature (using data over a small rotational speed range) and the values plotted have been averaged in bins corresponding to increments of $0.1 \mathrm{~m} / \mathrm{s}$. In practice, monitoring of this trend would compare values against normal bounds determined from historic data. An increase in bearing temperature due to bearing wear or possibly shaft misalignment could then manifest itself by observations being consistently above the maximum level of the set normal bounds as a function of power output. The advantage of this approach compared to standard alarm levels is that it allows a larger degree of sensitivity, i.e., correction for ambient temperature and power output, which will naturally increase the bearing temperature.

Another approach is to detrend the data using not only ambient

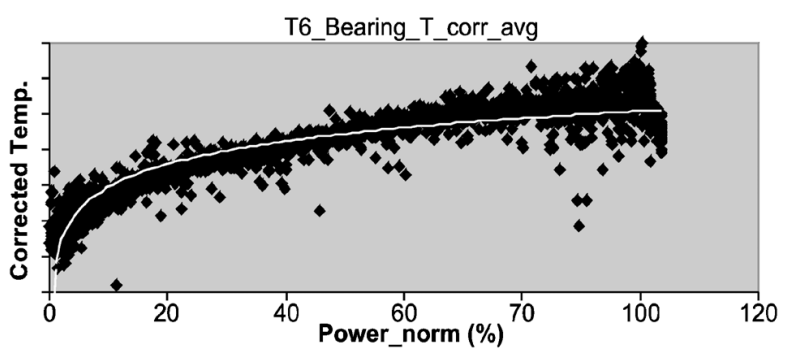

Fig. 6 Nordex N80 generator bearing temperature (corrected for ambient temperature) as a function of power output 



\section{Temperature Generator Bearing B - Moving Average}

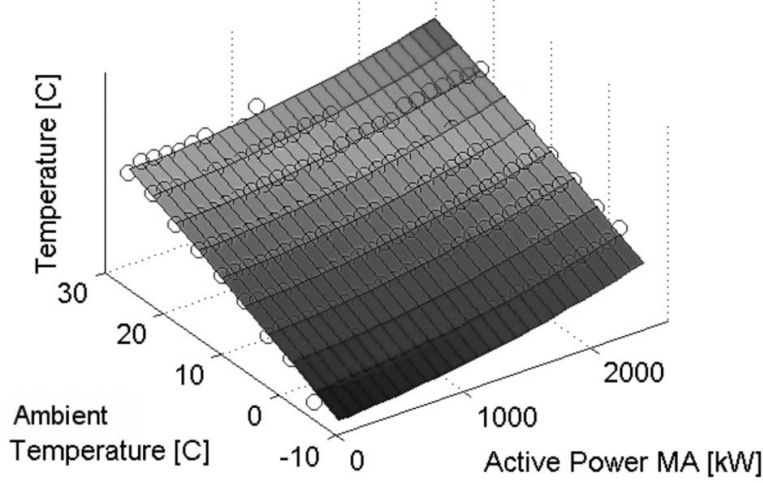

Fig. 7 Example of detrending of SCADA data

temperature but also the electrical power (see Fig. 7).

Figure 8 presents a similar plot that shows $10 \mathrm{~min}$ averaged nacelle accelerometer ( $z$ direction) axial vibration measurements as a function of the square of the wind speed (as a proxy for thrust).

In both cases, clear trends can be seen, and the value in terms of condition monitoring is to establish acceptable bounds for the trend lines that may be determined from the standard deviation of points around the trend lines during periods of known "normal operation." Subsequent measurements outside these bounds would trigger an analysis of the data point and comparison with other measurements (e.g., high frequency vibration measurements) to confirm possible operational problems. An example of abnormal behavior might be an increasing drive-train misalignment resulting in points significantly and consistently above the normal operating envelope about the straight line fit in Fig. 8.

Although the effectiveness of these methods could not be demonstrated in the project because no major failures occurred, it is already clear that the processed signals are limited within narrow bounds and are presented orderly in the form of monthly plots, which makes it easier to detect coming failures of the turbines. This will help operators to analyze their SCADA data more accurately and quickly. Obviously, more experience with these methods is needed, e.g., in order to define proper bounds for normal operation of each signal. It was concluded that processing SCADA data could be beneficial, but due to the limited measurement time and due to the fact that no real failure has occurred during the CONMOW experiments, no proof was found that processing SCADA data meets the criteria given in Sec. 2.3.

6.3 Drive-Train Vibration Monitoring. Signals have been correlated and sorted with the wind turbine status parameters, active power, wind speed, yaw error, etc. Prüftechnik detected a

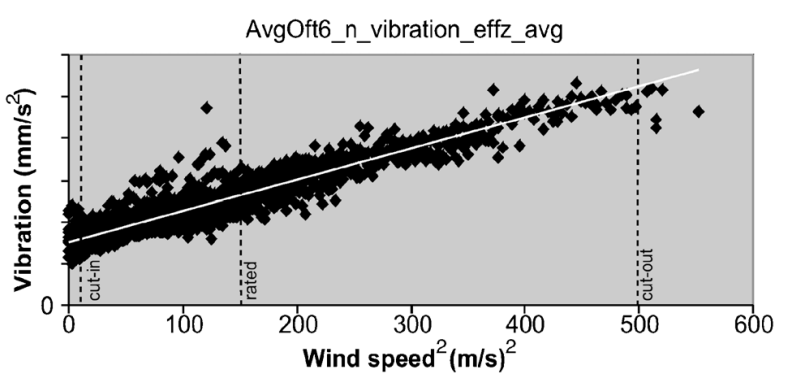

Fig. 8 Nordex N80 nacelle accelerometer axial vibration as a function of the square of wind speed mechanical vibration incitation associated with a failure of the generator bearing in an early stage in December 2005. This could be caused by a shaft misalignment problem. Corrective maintenance was carried out in May 2006, but the misalignment could not be fully corrected.

It was concluded that drive-train vibration monitoring indeed detected a failure at an early stage (criterion 1). Unfortunately, it was not possible to determine the severity (criterion 3) and to make an estimate of the degradation speed (criterion 2).

\section{Added Value Assessment}

To investigate the economic benefits of condition monitoring techniques on the expected O\&M effort, cost estimates have been made for a fictitious but realistic offshore wind farm defined as 100 turbines of 2.5 MW with some adjustments for offshore, such as a small platform crane above the splash zone. The wind farm is located in the North Sea at $15 \mathrm{~km}$ from a harbor from which the maintenance can be arranged. The wind and wave conditions for the location "IJmuiden Munitiestortplaats" [14,15] have been used. For the base line configuration, the failure rate is set to 4.5 failures per year per turbine, divided over five different maintenance categories of varying seriousness. For this base line configuration, the ECN O\&M Tool [16] has been applied to determine the long-term average effort and costs for maintaining the wind farm and to calculate the downtime and revenue losses.

Next, two different scenarios for condition monitoring have been considered. In the first scenario, the effect of early fault detection is addressed, and it is assumed that for a number of failures the consequence damage can be limited by applying condition monitoring techniques (less severe Failure repair class in Table 1). In this scenario, it is assumed that in case of an alarm, the turbine still has to be shut down. The effectiveness of the condition monitoring system has been considered by varying

- the capability of early detection (nondetected failures are set to $20 \%, 40 \%$, and $60 \%$ )

- the quality of the system (false alarms are set to $10 \%, 30 \%$, and $50 \%$ )

- the fraction of failures that can be repaired in a less severe maintenance category (for instance, for the repair a simple supply boat is then sufficient instead of a large crane ship and with less material costs)

In the second scenario, it is assumed that after an alarm the turbines are inspected. Based on the results of the inspection, it is decided whether it is allowed to keep the turbine in operation for some time, so that the maintenance can be carried out at a suitable time. This scenario is a further completion of scenario 1 , with the following aspects being considered:

- the fraction of failures for which the repair can be postponed while the turbine is kept in operation (the fraction is set to $20 \%, 40 \%$, and $60 \%$ )

- the period during which the turbine can be kept in operation after a degradation has been detected (delays of 1, 3, 6, and 12 months)

For the base line, the availability has been calculated as $90.0 \%$, which corresponds to a revenue loss of about $€ 70,000$ per year per turbine. All variants for both scenarios have been analyzed by the ECN O\&M tool, where the results have been split up for the main subsystems (gearbox, generator, etc.). As the results of these analyses strongly depend on the assumptions made for the base line, the effect for the different variants is calculated as the relative improvement as compared to the base line. As an example of scenario 1 , the reduction in revenue losses and the reduction in repair costs for the gearbox are depicted in Fig. 9.

The reduction is given as a function of the fraction of nondetected failures and the number of false alarms, while the fraction of failures that can be shifted to a less severe maintenance cat- 


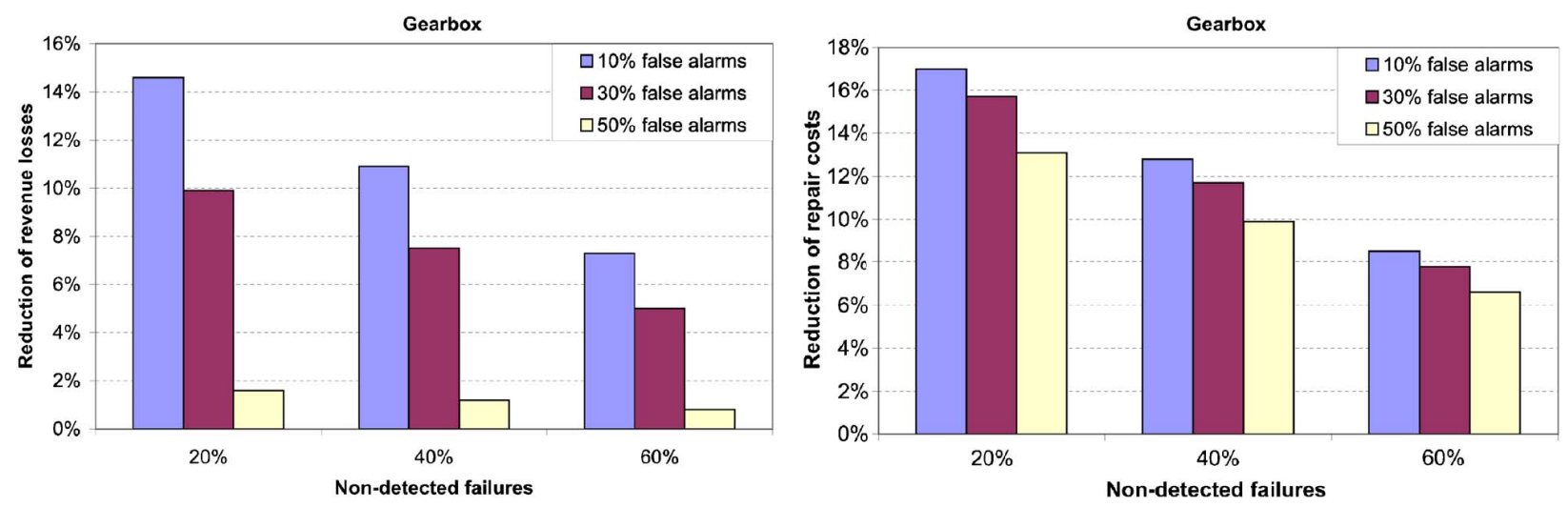

Fig. 9 Relative reduction in revenue losses and repair costs as a function of the fractions of nondetected failures and false alarms. The fraction of failures that can be shifted to a less severe maintenance category is set to $60 \%$.

egory equals $60 \%$. Based on this type of analyses, decisions can be made about the technical requirements to be demanded for a condition monitoring system in relation to investments to be made to install and operate such a system.

\section{Conclusions and Recommendations}

The CONMOW project was defined mainly to assess the added value of condition monitoring techniques (both online and offline) for optimizing the O\&M strategies for offshore wind farms. This was done among others by installing online condition monitoring systems for measuring drive-train vibrations, by analyzing SCADA data, and by analyzsing time series at $32 \mathrm{~Hz}$. The measurements were carried out at a GE $1.5 \mathrm{~S}$ turbine and five Nordex N80 turbines.

8.1 Conclusions. Taking into account the limitations mentioned above, the following conclusions were drawn from the CONMOW project.

- A FMECA has proven to be an effective way to determine which components are expected to contribute largely to the annual O\&M costs. In addition, the FMECA identifies the failure modes of these components, and for failure modes that show up gradually, it can be easily assessed if condition monitoring could be a means to reduce the O\&M costs. If so, it should be assessed if adequate condition monitoring systems are available and if they are demonstrated already in practice.

- At present, drive-train monitoring systems that operate reliably are commercially available. It was demonstrated that these systems are able to detect (1) component errors at an early stage and (2) off-design conditions such as shaft misalignment. An assessment whether the measurements exceeded critical levels and a prognosis of the remaining life could not be made due to insufficient knowledge of the degradation.

- Time series have been analyzed in various ways. Most promising results were obtained by using the wavelet transformations of the power output signal. The results showed increasing amplitude of certain frequency components that indicate generator rotor imbalance. Combining the results with maintenance information, it turned out that the changes were most likely caused by a shaft misalignment. This was confirmed later on by an analysis of vibration measurements. Similar to the vibration measurements, no assessment could be made whether the measurements exceeded critical levels and no prognoses could of the remaining life. Again, this was caused by insufficient knowledge of the degradation.

- Promising methods and algorithms have been developed to process 10 min averaged SCADA data. Detrending the data results in graphs with little scatter, which makes it easier to assess if parameters (e.g., temperatures or accelerations) are changing slowly over time. Such changes could be an indication of component degradation. Due to the limited measurement time during which no failures occurred in the turbines, no proof was found that the methods, indeed, are useful to determine failures at an early stage and to estimate the remaining lifetime.

- Within the CONMOW project, the response to abnormalities in the data was either more frequent inspections or an immediate shut down to avoid consequence damage.

- For all types of measurements (SCADA data, time series, vibration monitoring), it is concluded that large amounts of data that are difficult to interpret by wind farm operators are being produced. A dedicated expert team is required to derive meaningful recommendations for O\&M optimization.

- An economic assessment has been carried out to determine the benefits of condition monitoring systems. In fact, general conclusions cannot be drawn from this, but the method is able to quantify the added value, taking into account aspects such as false alarms, the capability of early detection, the fraction of failures that can be repaired in a less severe maintenance category, and the fraction of failures for which the repair can be postponed. Based on these types of analyses, decisions can be made about the technical requirements to be demanded for a condition monitoring system in relation to investments to be made to install and operate such a system.

- Standards for communications contribute to easier installation and compatibility of CM provisions. Configuration of $\mathrm{CM}$ systems requires significant effort.

Overall conclusions that were drawn from the CONMOW project are as follows.

(1) Especially, vibration monitoring systems are able to accurately determine which component in a drive train is failing. Such measurements are suitable to organize additional inspections and limit consequence damage.

(2) For all techniques tested in the CONMOW project, viz., analysis of time series, SCADA data, and vibration measurements, there was no sufficient knowledge in order to assess if critical limits were exceeded and how fast failures would develop. The latter two are minimum requirements to be fulfilled in order to change from calendar based maintenance to condition based maintenance.

8.2 Recommendations. It was concluded (and also confirmed by experiences outside the project) that at present there is insuf- 

ficient knowledge available on criteria to assess the green, yellow, and red status of a failure and to make prognoses on how the failures will develop over time. Such knowledge should be obtained from a larger population of identical wind turbines and longer measurement periods during which faults occur. It is therefore recommended to store data centrally so cross analyses and comparisons between turbines and sites can be made.

Drive-train vibration monitoring should be permanent and be made online since failures may develop within a period of time that is shorter than the regular maintenance interval. If failures are detected at an early stage, consequence damage can be avoided. Further, vibrations often show up under specific operating conditions.

The systems produce large amounts of data that are difficult and time consuming to interpret by wind turbine owners. The first analyses of raw data should be done by a dedicated expert team in order to derive information relevant for maintenance planning and feedback. Only this information should be provided to operators and design teams.

\section{Acknowledgment}

The CONMOW project was partly funded by the EC under Contract No. ENK5-CT-2002-00659 and by SenterNovem under Contract No. 2020-02-11-10-006. This paper is based on Ref. [17], and the authors want to thank the co-authors of this EWEC 2007 paper and their partners in the CONMOW project: Gregor Giebel, Risø National Laboratory (DK), Ed Norton, Garrad Hassan and Partners Ltd. (UK), Miguel Catalin Tipluica, Andrew MacLean, Pall Europe Ltd. (E), Axel Juhl Christensen, Gram \& Juhl A/S (DK), Edwin Becker, Pruftechnik CM GmbH (D), and Dirk Scheffler, Nordex Energy GmbH (D).

\section{References}

[1] Millborrow, D., 2006, "Operation and Maintenance Costs Compared and Revealed," Wind Stats Newsletter, 19(3).
[2] IEC-61400-25-1, -2, and -3, "Wind Turbines - Part 25: Communications for Monitoring and Control of Wind Power Plants," International Electrotechnical Commission, Geneva, 2006-12.

[3] "Communications for Monitoring and Control of Wind Power Plants," Report Nos. IEC-61400-25-1, IEC-61400-25-2, and IEC-61400-25-3.

[4] Cozens, N. J., and Watson, S. J., 2003, "State of the Art Condition Monitoring Techniques Suitable for Wind Turbines and Wind Farm Applications," Report for the CONMOW project, CREST/CONMOW/01/DOC

[5] Watson, S. J., Infield, D. G., and Xiang, J., 2008, "Condition Monitoring of Wind Turbines-Measurements and Methods," IET Renewable Power Generation, submitted.

[6] Non-Nuclear Energy-Joule II European Wind Turbine Standards Project, European Communities, Brussels, 1996, European Wind Turbine Standards: Project Results, EU, DG XII.

[7] Dalhoff, P., and Muuss, T., 2003, "Guideline for the Certification of Condition Monitoring Systems for Wind Turbines, Edition 2007," Germanischer Lloyd, Hamburg, 2007.

[8] Becker, E., and Schuhle, R., 2006, "Condition Monitoring on 'Small' Systems up to $1500 \mathrm{~kW}$," Erneuerebare Energien, Edition 6/2006, pp. 28-30.

9] Yang, S. J., 1981, Low-Noise Electrical Motors, Clarendon, Oxford.

[10] Vas, P., 1993, Parameter Estimation, Condition Monitoring, and Diagnosis of Electrical Machines, Clarendon, Oxford.

[11] Thiringer, T., 2001, "Periodic Pulsations From a Three-Bladed Wind Turbine," IEEE Trans. Energy Convers., 16(2), pp. 128-133.

[12] Tsai, C.-S., Hsieh, C.-T and Huang, S.-J., 2006, "Enhancement of DamageDetection of Wind Turbine Blades Via CWT-Based Approaches," IEEE Trans. Energy Convers., 21(3), pp. 776-781.

[13] Huang, S.-J., and Hsieh, C.-T., 1999, "High-Impedance Fault Detection Utilizing a Morlet Wavelet Transform Approach," IEEE Trans. Power Deliv., 14(4), pp. 1401-1407.

[14] Ministerie van Verkeer en Waterstaat, Monitoring van de Waterstaatkundige Toestand des Lands (MWTL), Data YM6, (www.golfklimaat.nl).

[15] Braam, H., and Eecen, P. J., 2005, "Assessment of Wind and Wave Data Measured at IJmuiden Munitiestortplaats," Report No. ECN-C-05-060.

[16] Rademakers, L. W. M. M., Braam, H., Obdam, T. S., Frohboese, P., and Kruse, N., 2007, "Tools for Estimating Operation and Maintenance Costs of Offshore Wind Farms," Paper Presented at the Hamburg Offshore Wind Conference, Sept. 6.

[17] Wiggelinkhuizen, E., Vergruggen, T., Braam, H., Rademakers, L., Xiang, J., Watson, S., Giebel, G., Norton, E., Hassan, G., Tipluica, M. C., MacLean, A., Christensen, A. J., Becker, E., and Scheffler, D., 2007, CONMOW: Condition Monitoring for Offshore Wind Farms, Paper Presented at the European Wind Energy Conference 2007, Milan, May 7-10. 
